\section{MIDPI sciforum}

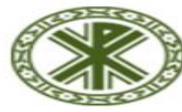

Universidad Católica

de Valencia

\& > International > About us

\section{International}

IWIMSM-03: Iberoamerican Workshop on Model. and Simulation Methods, Valencia, Spain, 2019

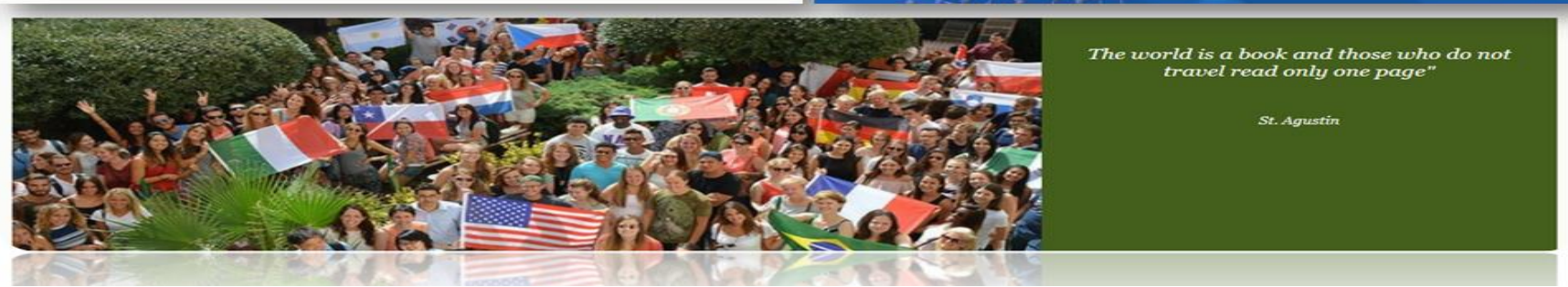

\title{
Model representation of diffusion near the triple point of argon
}

\author{
N. Atamas ${ }^{a}$, D. A. Gavryushenko ${ }^{a}$, K. S. Yablochkova ${ }^{a}$, M. M. Lazarenko ${ }^{a}$ \\ ${ }^{a}$ National Taras Shevchenko University of Kyiv, Kyiv, Ukraine
}

\begin{tabular}{|l|l|}
\hline \multicolumn{1}{|c|}{ Graphical Abstract } & $\begin{array}{l}\text { Abst. } \\
\text { We present a systematic study of the effect of } \\
\text { temperature and pressure on the microscopic } \\
\text { dynamics of argon near the triple point. We also } \\
\text { provide a detailed description of the argon } \\
\text { diffusion model and discuss the time-dependent } \\
\text { dynamics of argon, as well the relaxation } \\
\text { processes in the temperature and pressure range } \\
\text { near the argon's triple point. The main goal of } \\
\text { this work is to develop a method for determining } \\
\text { the P-T parameters on the coexistence curve, for } \\
\text { which there is a transition from a mixture ("solid } \\
\text { (glass)- dense liquid" ) } \rightarrow \text { (dense liquid" } \rightarrow \\
\text { "liquid") } \rightarrow \text { ("liquid" -gas). We present and } \\
\text { compare the results of a dynamic analysis of the } \\
\text { system in various states obtained using several } \\
\text { approaches. } \\
\text { Keywords } \\
\text { argon, triplet point, diffusion model, MD simulation }\end{array}$ \\
\hline
\end{tabular}

Conflicts of Interest: The author declares no conflict of interest. 


\section{References}

1. Woodcock, Leslie V., Fluid phases of argon: A debate on the absence of van der Waals' "critical point", Natural Science, 20135 (2), 194-206. http://dx.doi.org/10.4236/ns.2013.52030.

2. Past Michael F., Zwolinski Bruno J. Computation of the transport coefficients of dense fluid neon, argon,krypton and xenon by molecular dynamics, Molecular Physics, 1991 73( 3), 471-481.

3. Bandyopadhyay A. K., Sharma J. K. N. and Gopal E. S. R. Effect of liquid phase on the triple point pressure of argon. Pramana - J. Phys. 1992 38(4), 335-341.

4. Shor S., Yahel E., Makov G. Evolution of short range order in Ar: Liquid to glass and solid transitions-A computational study. AIP Advances 2018 8, 045215.

5. M. P. Allen and D. Y. Tildesley, Computer Simulation of Liquids. Oxford. UK, Clarenton Press, 2010.

6. T. R. Forester, The DL-POLY-4.0., Daresbury Laboratory, UK. http://www.scd.stfc.ac.uk/SCD/44516.aspx.

7. H. J. C. Berendsen, J. R. Grigera and T. P. Straatsma, J. Phys. Chem., 1987, 91, 6269- 6271.

8. T. Schlick, Molecular Modeling and Simulation: An Interdisciplinary Guide. Interdisciplinary Applied Mathematics, Mathematical Biology, Springer-Verlag, 2002.

9. V. V. Brazhkin and K. Trachenko, J. Phys. Chem. B., 2014, 118, 11417.

10. V. V. Brazhkin, A. G. Lyapin, V. N. Ryzhov, K. Trachenko, Y. D. Fomin and E. N. Tsiok, Phys.Uspekhi., 2012, 55, 1061-1079.

11. Atamas N., Gavryushenko D., Yablochkova K.S. Temperature and temporal heterogeneities of water dynamics in the physiological temperature range. Journal of Molecular Liquids, 2021 340, 117201. https://doi.org/10.1016/j.molliq.2021.117201 